\title{
Harmonization of Finnish Vaccination Data
}

\author{
Riikka VUOKKO ${ }^{\mathrm{a} 1}$, Anne VAKKURI ${ }^{\mathrm{b}}$ and Sari PALOJOKI ${ }^{\mathrm{a}}$ \\ ${ }^{a}$ The Ministry of Social Affairs and Health, Finland \\ ${ }^{b}$ Helsinki University Hospital (HUS), Peijas Hospital, Finland
}

\begin{abstract}
Vaccination information is needed at individual and at population levels, as it is an important part of public health measures. In Finland, a vaccination data structure has been developed for centralized information services that include patient access to information. Harmonization of data with national vaccination registry is ongoing. New requirements for vaccination certificates have emerged because of COVID-19 pandemic. We explore, what is the readiness of Finnish development of vaccination data structures and what can be learned from Finnish harmonization efforts in order to accomplish required level of interoperability.
\end{abstract}

Keywords. Vaccination, data structure, classification, data repository, case study

\section{Introduction}

In Europe, immunisation information systems (IIS) and digital vaccination records have been built along with national vaccine-programmes [1]. Vaccination information is needed both at individual and population levels, as it is an important part of public health measures. With digital records, individuals can make informed decisions on vaccination, and population level data can be utilized e.g. vaccination programmes and better public health. [2] In Finland, the national vaccination registry is controlled and administered by the Finnish Institute for Health and Welfare (THL). The registry data enables data on national and regional vaccination coverage, monitoring of changes, and examination of vaccination coverage per population group and period of time. [3] Parallel with development of registry data, over a decade, Finland has been developing common data structures to be used in electronic health record systems (EHR) and in centralized Kanta eHealth services infrastructure. A future goal is that interoperable Kanta patient archive content could be used for registry data retrieval instead of separate data gathering processes. The respective data elements are to be harmonized to achieve interoperable use. Currently, COVID-19 strategies have emphasized vaccination as a crucial tool in controlling the pandemic. This has caused an urgent need to prioritize and speed up development of Kanta vaccination data structure in order to acquire more accessible vaccination data not only for professionals but also for individuals.

As a joint effort, in December 2020, the European Council proposed a coordinated approach for interoperability (IOP) elements with a goal of interoperable vaccination certificates. The collaboration with Member States is led by the EU eHealth Network, with the EU Health Security Committee, the European Medicines Agency, European

1 Corresponding Author, Dr. Riikka Vuokko, P.O. Box 33, 00023 Helsinki, Finland; E-mail: riikka.vuokko@gmail.com. 
Centre for Disease Prevention and Control and World Health Organization joining the discussions. [4] Decisions on vaccination interoperable elements are expected during the spring 2021.

In this paper, we set out to analyse Kanta vaccination data structure with 23 elements (see Table 1) developed for common use in Finland in the light of emerging needs during COVID-19 pandemic. We also explore data harmonization effort for interoperable vaccination data for the clinical and epidemiological use. Therefore, our research questions are (1) What is the readiness of Finnish development of vaccination data structures in EU collaboration for interoperable data elements of digital vaccine certificate, and (2) What can be learned from harmonization of the national data structure and vaccination registry contents to reach EU interoperability requirements.

\section{Methods}

In this paper, we explore vaccination data structures and their development with a Finnish case study. Although case studies can mean diverse approaches and no uniform methodology can be applied, case studies require planning and documenting [5]. In order to build our case study, we first provide contextual information as suggested by Kaplan and Duchon [6] to support reliability of the observations. In Finland, patient data is stored in Patient Data Archive in the Kanta eHealth services. Kanta provides Information Management Service (IMS) that compiles central patient data from the archive into lists, such as lists of patient's diagnosis, procedures, measurements, risk information, test results as well as vaccinations. The compiled information by IMS, "a vaccination list" is shown to individuals in MyKanta-pages patient portal. Therefore, in Kanta, clinically relevant patient data is structured for interoperability. In Kanta, types of data elements are defined with HL7 clinical standard (see column 2 in Table 1). These data structures and respective classifications are published and maintained by THL's Code Service, which is a cornerstone for building a successful digital health infrastructure in Finland. [7] In development of common data structures, the Code Service personnel and clinical experts are collaborating closely. However, our case study is limited to the data structure analysis, not on the collaborative efforts by numerous expert groups.

Based on our research questions, we set out to conduct a descriptive case analysis [6]. To form our research data, we gathered development documentation and specifications 2013 onwards for an analysis. Vaccination data structures were analysed based on the Code Service publications and with reflection to various aspects of the development. What comes to our position as researchers, two of the authors act as informatics and data structure experts, who were developing the Code Service and the common data structures, such as vaccination structures, and are currently steering national development. The third author is a senior medical officer and a clinician having first-hand experience of use and usability of the common data structures to be implemented in the EHRs in Finland.

\section{Results}

Currently, vaccine information is documented under the heading "Prevention" with national classifications. The vaccination data elements are described in column 1 and 
respective classification in column 3 (see Table 1). In 2021, IMS will start compiling and populating the vaccination list utilizing the structured data elements. For individuals this means better usability of vaccination information in MyKanta-pages. A future goal is to provide individuals with a digital vaccination card through MyKantapages.

Table 1. Structured content of vaccination data in Finland based on the national Kanta requirements. The column "National registry" documents the respective registry content. The column "EU IOP draft" shows respective data elements for minimum data of vaccination certificate excluding patient data and metadata.

\begin{tabular}{|c|c|c|c|c|}
\hline $\begin{array}{l}\text { Long name of data } \\
\text { element in Kanta }\end{array}$ & $\begin{array}{l}\text { HL7 data type } \\
\text { used in Kanta }\end{array}$ & $\begin{array}{l}\text { Classification } \\
\text { used in Kanta }\end{array}$ & $\begin{array}{l}\text { National } \\
\text { registry* }\end{array}$ & EU IOP draft* \\
\hline $\begin{array}{l}\text { Vaccine generic name } \\
\text { and code }\end{array}$ & CodedValue & ATC & $\mathrm{Y}$ & $\mathrm{Y}$ \\
\hline $\begin{array}{l}\text { Vaccine product brand } \\
\text { name }\end{array}$ & String & not applicable & Y & $\mathrm{Y}$ \\
\hline $\begin{array}{l}\text { Article number of } \\
\text { package }\end{array}$ & InstanceIdentifier & Package id & Y & $\mathrm{N}$ \\
\hline Package lot number & String & not applicable & Y & $\mathrm{Y}$ \\
\hline $\begin{array}{l}\text { Version of } \\
\text { pharmaceutical } \\
\text { database }\end{array}$ & InstanceIdentifier & Version id & $\mathrm{N}$ & $\mathrm{N}$ \\
\hline $\begin{array}{l}\text { Disease vaccine } \\
\text { protects against }\end{array}$ & CodedValue & $\begin{array}{l}\text { Disease vaccine } \\
\text { protects against }\end{array}$ & Y & $\mathrm{N}$ \\
\hline $\begin{array}{l}\text { Extension of vaccine } \\
\text { preventable disease }\end{array}$ & String & not applicable & Y & $\mathrm{N}$ \\
\hline Dose ordinal $\mathrm{nr}$ & IntegerNumber & not applicable & Y & $\mathrm{Y}$ \\
\hline Dose (value and unit) & $\begin{array}{c}\text { Interval } \\
\text { PhysicalQuantity }\end{array}$ & not applicable & $\mathrm{N}$ & $\mathrm{N}$ \\
\hline Vaccination route & CodedValue & Vaccination route & Y & $\mathrm{N}$ \\
\hline Vaccination site & CodedValue & Vaccination site & Y & $\mathrm{N}$ \\
\hline Vaccine administrator & PersonName & not applicable & $\mathrm{N}$ & $\mathrm{N}$ \\
\hline $\begin{array}{l}\text { Vaccinator service } \\
\text { providert }\end{array}$ & InstanceIdentifier & $\begin{array}{c}\text { Organization } \\
\text { registry/service } \\
\text { provider identifier }\end{array}$ & $\mathrm{N}$ & $\mathrm{Y}$ \\
\hline Date of administration & PointInTime & not applicable & Y & $\mathrm{Y}$ \\
\hline $\begin{array}{l}\text { Adverse effects of } \\
\text { vaccination }\end{array}$ & CodedValue & not applicable & $\mathrm{Y}$ & $\mathrm{N}$ \\
\hline $\begin{array}{l}\text { Code for external cause } \\
\text { of adverse effects }\end{array}$ & CodedValue & not applicable & Y & $\mathrm{N}$ \\
\hline $\begin{array}{l}\text { Date of adverse effect } \\
\text { observed }\end{array}$ & PointInTime & not applicable & $\mathrm{N}$ & $\mathrm{N}$ \\
\hline Additional information & String & not applicable & $\mathrm{N}$ & $\mathrm{N}$ \\
\hline Source of information & CodedValue & $\begin{array}{c}\text { Source of } \\
\text { information }\end{array}$ & $\mathrm{N}$ & $\mathrm{N}$ \\
\hline Clinical trial vaccine & Boolean & not applicable & $\mathrm{N}$ & $\mathrm{N}$ \\
\hline $\begin{array}{l}\text { Clinical trial vaccine } \\
\text { identifier }\end{array}$ & String & not applicable & $\mathrm{N}$ & $\mathrm{N}$ \\
\hline $\begin{array}{l}\text { Vaccination's unique } \\
\text { identifier }\end{array}$ & InstanceIdentifier & Vaccination id & $\mathrm{N}$ & $\mathrm{N}$ \\
\hline $\begin{array}{l}\text { Market authorization } \\
\text { holder }\end{array}$ & not available & not applicable & $\mathrm{N}$ & planned \\
\hline Country of vaccination & CodedValue & Country & $\mathrm{Y}$ & $\mathrm{Y}$ \\
\hline
\end{tabular}

The structured data elements for Kanta (see Table 1) include information of the vaccination and where and by whom it was administered. When analysing the data elements, national context of the development is evident. Only two international 
classifications are used, namely the International Classification for Diseases Version 10 (ICD-10) and the Anatomical Therapeutic Chemical (ATC) Classification System for active ingredients for drugs and vaccines. These classifications are controlled by the WHO. In Finland, localized versions are in use. All other classification are of a national origin. With the data structure, it is possible to record additional information such as an adverse event in a free text format. Especially concerning vaccination information, patients may have an important role in informing a vaccination history. For example, the patient can remember that a tetanus shot was administered in a specific year, but no specific information such as the name of the vaccine can be given. Therefore, coding for source of information was added into the structure to record partial information.

When comparing the Kanta data elements to registry data elements (column 4 in Table 1), differences in purposes for use and development history are apparent. The registry data is more limited and initially, the structure did not utilize HL7 standard. Vaccination registry data has been collected from the patient records for longer time than Kanta has been in production. Although vaccination data has been collected since over ten years, reliable impact assessment is only possible when data quality is reviewed and monitored. Patient data is updated daily into the registry, and data completeness is monitored. An alert system reports unexpected changes in data accumulation prompting the validation of observed changes in vaccination coverage. [8]

Instead of separate data gathering from EHRs into the vaccination registry, Kanta services could provide registry data in the future. This would decrease the care providers' documentation workload. Currently there are two separate documenting processes to gather data into registry and to store it into Kanta. A precondition to change these processes is that the vaccination data in both systems is harmonized at data element level for interoperability. The harmonization process has been slow due to different development histories and use purposes. Previously, HL7 standardized data types were not applied in the registry and the registry utilized different classifications. In practice, the harmonization process is still ongoing and will require mapping of data elements and classifications to align the contents. For example, disease that vaccine protects against is coded in the national registry based on mapping with two additional national classifications that are not currently used in Kanta.

Regarding the European guideline [4] for vaccination data (see column 5 in Table 1), Finnish development corresponds the goals well. For example, a vaccination can be coded with either ATC codes or the SNOMED CT terminology. Both are available in Finland, although SNOMED CT is not currently required for vaccination data. Instead of simple dose ordinal number, the certificate should include numbers in a series (e.g., 1 out of 2). Additionally, the certificate proposal includes e.g., person name and/or optional person identifier, date of birth, certificate authorization and metadata. As development is still ongoing, further optional data elements such as name of the disease will be added. Further specification work is carried out for the technical certification and legal issues to achieve required trust. Additional data elements are producible in EHRs although they are not in the national vaccination data structure.

\section{Discussion}

Based on our analysis, Finnish readiness to provide required content for an interoperable vaccination certificate is on a promising track, although Finnish language 
is a challenge. Most likely international certificate would require e.g., English or French translations. Currently, the data structure specifications and classifications are available only in Finnish and Swedish in the Code Service. The European preparation for common data elements is encouraging in a sense that not all elements are mandatory for the certificate. It is possible to add country-specific elements. In Finland, the Code Service is a cornerstone in distributing possible requirement changes efficiently and in a uniform manner into all EHR systems. Additionally, available collaboration methods support outlining and assessing other needed elements, such as defining the national approach for vaccination certificates production and validation.

However, an additional need from ECDC is to get up to date vaccination registry data from all Member States. In this regard, further data elements are most likely required in order to acquire comparable and evidence-based data for public health evaluation to maximize the benefits and to manage financial pressures. Moreover, ongoing collaboration for European health data infrastructure supporting exchange of vaccination data requires renewal of current classifications. [1] Thus, it is important for all Member States to participate in discussion of interoperable data and their possible use cases in order to foresee changes in data structures.

Our case study implicates that future research is needed to explore various use cases or needs regarding vaccination data. Especially, in 2021, interoperable vaccination information at national and international level emerges as part of individuals rights and needs. Careful consideration of possible related ethical and legal factors is required. We conclude that international efforts to develop common standards for interoperability are needed more than ever to answer future public health needs.

\section{References}

[1] Sheikh S, Biundo E, Courcier S, Damm O, Launay O, Maes E, Marcos C, Matthews S, Meijer C, Poscia A, Postma M, Saka O, Szucs T, Begg N. A report on the status of vaccination in Europe. Vaccine. 2018 Aug 9;36(33):4979-4992. doi: 10.1016/j.vaccine.2018.06.044. Epub 2018 Jul 4. Erratum in: Vaccine. 2019 Feb 28;37(10):1374-1376. PMID: 30037416.

[2] European Centre for Disease Prevention and Control ECDC. Information systems to record information about vaccination, 19.11.2018. https://www.ecdc.europa.eu/en/immunisation-vaccines/immunisationinformation-systems.

[3] Finnish Institute for Health and Welfare THL. Finnish National Vaccination Register and monitoring of the vaccination programme, 2.1.2021. https://thl.fi/en/web/infectious-diseases-andvaccinations/surveillance-and-registers/finnish-national-vaccination-register-and-monitoring-of-thevaccination-programme.

[4] eHealth Network - Guidelines on proof of vaccination for medical purposes - basic interoperability elements,V1.1, 2021.01.27. https://ec.europa.eu/health/sites/health/files/ehealth/docs/vaccinationproof_interoperability-guidelines_en.pdf.

[5] van der Blonk H. Writing Case Studies in Information Systems Research. Journal of Information Technology. 2003;18(1):45-52. doi:10.1080/0268396031000077440.

[6] Kaplan B., Duchon D. Combining Qualitative and Quantitative Methods in Information Systems Research: A Case Study. MIS Quarterly. 1988; 12(4), 571-586. doi:10.2307/249133.

[7] Vuokko R, Mäkelä-Bengs P, Härkönen M. Improving health care service delivery with a national code service. Stud Health Technol Inform. 2014;205:323-7. PMID: 25160199.

[8] Baum U, Sundman J, Jääskeläinen S, Nohynek H, Puumalainen T, Jokinen J. Establishing and maintaining the National Vaccination Register in Finland. Euro Surveill. 2017;22(17):pii=30520. DOI: http://dx.doi.org/10.2807/1560-7917.ES.2017.22.17.30520. 